\title{
PEMBELAJARAN BIPA (BAHASA INDONESIA PENUTUR ASING) DALAM UPAYA INTERNASIONALISASI UNIVERSITAS DI INDONESIA PADA ERA GLOBALISASI
}

\author{
oleh: \\ Suwandy Tanwin \\ Program Studi Pascasarjana Pendidikan Bahasa Indonesia \\ Fakultas Keguruan dan Ilmu Pendidikan \\ Universitas Prima Indonesia \\ (suwandytan83@gmail.com)
}

\begin{abstract}
ABSTRAK
Keberadaan bahasa Indonesia sebagai bahasa internasional di kancah internasional sudah tidak dapat diragukan lagi. Terdapat beberapa universitas di wilayah Asia, Australia dan daratan Eropa memberikan pembelajaran Bahasa Indonesia sebagai salah satu mata kuliah yang wajib ditempuh. Salah satu upaya untuk membawa bahasa Indonesia di kancah Internasional salah satunya yaitu melalui pembelajaran BIPA. Penggunaan bahasa Indonesia dalam kegiatan pendidikan di Indonesia telah diatur dalam UU No. 24 Tahun 2009, khususnya pasal 29 ayat (1). Hal tersebut berlaku pula pada program pengajaran BIPA di Indonesia. Oleh karena itu mahasiswa asing yang belajar atau menuntut ilmu bahkan yang bekerja di Indonesia, harus mampu menguasai penggunaan bahasa Indonesia tersebut. salah satu cara agar mahasiswa asing tersebut dapat menggunakan bahasa Indonesia dalam kehidupan sehari- harinya yaitu melalui program BIPA. Sebelumnya BIPA memang dijadikan salah satu upaya untuk internasionalisasi bahasa Indonesia. Jadi, selain dapat membawa bahasa Indonesia sebagai bahasa internasional, program BIPA juga dapat dimanfaatkan dalam upaya internasionalisasi universitas-universitas di Indonesia khususnya pada era globalisasi saat ini. Bertambahnya pelajar BIPA dapat dimanfaatkan untuk memperkenalkan bahasa Indonesia bagi pelajar asing lainnya agar tertarik untuk mempelajarinya.
\end{abstract}

Kata Kunci: BIPA, internasionalisasi, globalisasi, universitas

\begin{abstract}
The existence of Indonesian as an international language in the international arena cannot be doubted. There are several universities in Asia, Australia and mainland Europe that provide Indonesian language learning as one of the compulsory courses. One of the efforts to bring Indonesian to the international arena is through BIPA learning. The use of Indonesian in educational activities in Indonesia is regulated in Law no. 24 of 2009, especially Article 29 paragraph (1). This also applies to the BIPA teaching program in Indonesia. Therefore, foreign students studying or studying and even working in Indonesia, must be able to master the use of the Indonesian language. one way that foreign students can use Indonesian in their daily life is through the BIPA program. Previously, BIPA was used as an effort to internationalize the Indonesian language. So, in addition to being able to bring Indonesian as an international language, the BIPA program can also be used in efforts to internationalize universities in Indonesia, especially in the current era of globalization. The increase in BIPA students can be used to introduce Indonesian to other foreign students so that they are interested in learning it.
\end{abstract}

Key Words: BIPA, internationalization, globalization, university

\section{PENDAHULUAN}

Bahasa Indonesia saat ini memegang peranan penting dalam kedudukannya sebagai bahasa asing di tengah masyarakat internasional. Pemerintah daerah Ho Chi
Minh City, Vietnam, menempatkan bahasa Indonesia sebagai bahasa asing kedua sejak Desember 2007. Bahasa Indonesia juga digunakan di negara-negara berbahasa Melayu, seperti Malaysia, 
Singapura, Brunei Darussalam, dan masyarakat di benua lain. Diperkirakan ada 45 negara mengajarkan bahasa Indonesia kepada siswa atau mahasiswa, antara lain, Australia, Amerika, Kanada, Vietnam, Rusia, Korea, Jepang, dan Jerman. Untuk Australia, bahasa Indonesia menjadi bahasa asing terpopuler keempat (kompas.com, 2009).

Dalam perkembangannya, bahasa Indonesia sekarang sudah memberikan andil yang signifikan bagi bangsa Indonesia. Hal ini terlihat dari semakin besarnya bangsa lain tertarik untuk mempelajari bahasa Indonesia. Berdasarkan data Kementerian Luar Negeri pada tahun 2012, bahasa Indonesia memiliki penutur asli terbesar kelima di dunia, yaitu sebanyak 4.463 .950 orang yang tersebar di luar negeri.

Tidak hanya itu, menurut Kepala Badan Pengembangan dan Pembinaan Bahasa, Kementerian Pendidikan dan Kebudayaan, Mahsun, beliau mengatakan bahwa saat ini setidaknya ada 45 negara yang menjadi peserta BIPA, dengan 174 tempat pelaksanaan BIPA yang tersebar di berbagai negara dan paling banyak di Australia (kompas.com, 2013).

Arus globalisasi tidak selamanya membawa dampak negatif. Menurut Pieterse dan Robertson (dalam Astika, 2015: 88) menyimpulkan bahwa globalisasi tidak seharusnya dicurigai sebagai sebuah proses yang negatif, dalam arti proses domininasi dari yang global terhadap yang lokal. Banyak contoh fenomena yang menunjukkan bahwa dalam arus globalisasi terdapat proses yang positif. Salah satunya yaitu dalam aspek bahasa. Di tengah arus globalisasi, Indonesia termotivasi untuk menjadikan bahasanya sebagai salah satu bahasa internasional, misalnya melalui pembelajaran bahasa Indonesia di universitas-universitas di dalam negeri maupun luar negeri.

Selain pemerintah pusat, peran berbagai pihak juga bertanggung jawab untuk upaya internasionalisasi bahasa Indonesia tersebut. Salah satu upaya internasionalisai bahasa Indonesia tersebut telah ditunjukkan melalui pembelajaran BIPA dalam universitas-universitas di dalam maupun luar negeri. Hal tersebut sesuai dengan penyampaian Muliastusi (2016: 8) bahwa internasionalisasi bahasa Indonesia dapat ditingkatkan melalui pembelajaran BIPA yang didukung oleh semua lembaga yang relevan. Pembelajaran BIPA tidak hanya dilakukan di dalam negeri, tetapi juga di luar Indonesia. Hal tersebut pada akhirnya membawa dampak positif bagi bahasa Indonesia, yaitu baik jumlah penutur dan area penggunaan bahasa Indonesia terus bertambah.

Penggunaan bahasa Indonesia dalam pendidikan di Indonesia telah diatur dalam UU No. 24 Tahun 2009, khususnya pasal 29 ayat (1) yang menyatakan bahwa bahasa Indonesia wajib digunakan sebagai bahasa pengantar dalam pendidikan nasional. Jadi, baik warga negara Indonesia maupun warga negara asing wajib menggunakan bahasa Indonesia ketika mengikuti program pembelajaran di negara Indonesia.

Berdasarkan uraian di atas, terlihat jelas bahwa program BIPA memiliki peran penting dalam upaya internasionalisasi universitas di Indonesia. Jumlah peminat BIPA yang semakin bertambah dapat dimanfaatkan sebagai upaya internasionalisasi universitas di Indonesia. Hal lain dapat diwujudkan melalui pengadaan jurusan atau mata kuliah BIPA di universitas-universitas di 
Indonesia. Semakin bertambahnya peminat BIPA, dapat menjadikan universitas di Indonesia berlayar di kancah internasional. Tulisan ini bertujuan untuk mengungkapkan bahwa program pembelajaran BIPA yang diadakan di universitas di Indonesia dapat membantu internasionalisasi bagi lembaga tersebut pada era globalisasi ini.

\section{PEMBAHASAN}

\section{Karakteristik Program dan Pelajar BIPA}

Pembelajaran BIPA adalah pembelajaran bahasa Indonesia yang subjeknya merupakan penutur asing. Pembelajaran BIPA lebih fokus pada pembelajarnya. Yang menjadi subjek pembelajar BIPA adalah orang asing atau penutur asing. Jadi, bahasa Indonesia merupakan bahasa asing bagi pembelajar BIPA. Pembelajaran BIPA menjadikan orang asing mampu dan menguasai bahasa Indonesia (Kusmiatun, 2016: 1). Sedangkan pelajar BIPA adalah pelajar dari luar negara Indonesia yang ingin belajar bahasa Indonesia. Pelajar tersebut umumnya terdiri dari warga negara asing yang belum mengerti dasar dan tata bahasa Indonesia tetapi tertarik untuk mempelajarinya. Hal tersebut didukung dengan pernyataan dari Suyitno (2008: 111) bahwa pelajar BIPA merupakan pelajar berkewarganegaraan asing yang berlatar belakang budaya berbeda dengan budaya bahasa yang diketahui dan dipelajarinya selama ini.

Pelajar BIPA dapat diumpamakan sebagai seorang anak yang belum mengerti bahasa yang akan digunakan di lingkungannya. Pengetahuan mereka tentang penggunaan bahasa Indonesia dengan benar dan baik masih sangat prematur. Hal sama disampaikan oleh Ulumuddin dan Wismanto (2014: 16) bahwa bahasa Indonesia untuk Penutur Asing dapat diibaratkan sebagai sosok bayi yang baru lahir dan perlu didewasakan. Proses pendewasaan tersebut harus dilakukan secara profesional dan diiringi dengan tanggung jawab keilmuan yang melibatkan berbagai pihak.

Sistem pembelajaran BIPA tentunya berbeda dengan pembelajaran bahasa Indonesia bagi penutur asli. Salah satu perbedaannya adalah dapat dilihat dari segi pelajar BIPA itu sendiri. Pelajar BIPA yang pada dasarnya adalah orang asing yang telah memiliki bahasa pertamanya (B1) dan memiliki latar belakang budaya yang sangat berbeda merupakan salah satu karakteristiknya. Tujuan para pelajar BIPA untuk belajar Bahasa Indonesia pun juga beragam. Ada beberapa pelajar yang hanya ingin mengerti percakapan praktis saja, misalnya empat keterampilan berbahasa yaitu menyimak, membaca, menulis, dan berbicara. Ada juga yang ingin mahir dalam berbahasa Indonesia. Usia pelajar BIPA yang beragam juga menjadi salah satu karakteristik yang harus diperhatikan demi kelancaran proses pembelajaran BIPA. Hal tersebut berhubungan dengan pendekatan, metode, teknik, dan media yang digunakan (Muliastuti, 2016: 4-5).

Pembelajaran BIPA bukan hanya mengajarkan tentang bahasa. Budaya juga memiliki porsi penting dalam proses pembelajarannya. Hal tersebut bertujuan untuk memudahkan pelajar BIPA dalam memahami Indonesia, karena bahasa dan budaya memiliki keterkaitan yang kuat dan tidak dapat dipisahkan. Menurut Koentjaraningrat (dalam Ruskhan, 2007: 5) terdapat beberapa aspek budaya yang dapat dimanfaatkan dalam penyajian materi ajar BIPA, yakni (1) sistem peralatan dan perlengkapan hidup; (2) 
sistem mata pencarian hidup; (3) sistem; (4) bahasa; (5) kesenian; (6) sistem pengetahuan; dan (7) sistem religi.

Lestyarini (2012: 3) berpendapat bahwa identitas kultural Indonesia sudah seharusnya disertakan dalam pembelajaran. Dengan mempelajari konteks budaya, kehidupan sosial, dan norma-norma sebagai nilai entitas masyarakat Indonesia, penutur asing dapat mempelajari karakter bangsa Indonesia yang merupakan syarat mutlak yang harus dilakukan atau dikenal dengan istilah sine qua non untuk mempelajari bahasa Indonesia. Hal tersebut menunjukkan bahasa merupakan salah satu cermin jati diri masyarakat sehingga kajian dan pembelajarannya tidak akan dapat pernah terlepas dari kehidupan masyarakat itu sendiri.

Berdasarkan kemampuannya pelajar BIPA terbagi menjadi tiga tingkatan, yaitu tingkat pemula, tingkat menengah dan tingkat lanjut. Materi yang diberikan pun berbeda, disesuaikan dengan tingkatannya. Menurut Suyitno (2007: 6869) bahwa materi bahasa yang dikembangkan dalam pembelajaran BIPA didasarkan pada tingkat kemampuan bahasa Indonesia pembelajarnya, misalnya untuk pengembangan materi membaca.

\section{Internasionalisasi dalam Dunia Pendidikan sebagai Dampak Arus Globalisasi}

Kualitas sumber daya manusia menjadi kunci daya saing antar negara di era globalisasi. Pendidikan dijadikan sebagai salah satu prioritas utama untuk meningkatkan daya saing bangsa dalam segala bidang. Ketergantungan antarnegara dalam berbagai aspek kehidupan semakin besar dan proses ini akan terus berlangsung di era globalisasi ini. Sehingga untuk dapat ikut berperan aktif dalam hubungan antarnegara di kancah internasional diperlukan keterampilan berkomunikasi dalam bidang bahasa yang menjadi sarana komunikasi antarbangsa (Astika, 2015: 88).

$$
\text { Lestyarini }
$$

mengungkapkan agar tidak tercerabut dari akar lokalitas, budaya, nasionalisme, internasionalisme yang disertai dengan landasan nilai-nilai dimensi spiritualitas maka diperlukan pegangan erat di setiap pribadi manusia dalam konteks akademis. Bagi orang-orang yang mengikuti arus globalisasi tanpa batasan dapat memberikan dampak yang cukup membahayakan. Di sisi lain, arus globalisasi mengalir semakin deras dan dapat mengakibatkan mereka tenggelam dalam arus tersebut dan menghilang tanpa karya.

Menurut Thoyib (2008: 221)
terdapat empat faktor utama yang menyebabkan terjadinya internasionalisasi pendidikan yaitu: (1) rendahnya perhatian pemerintah di bidang pendidikan; (2) negara-negara berkembang yang masih mengalami masalah tentang dana; (3) permintaan untuk meningkatkan mutu pendidikan tinggi; dan (4) teknologi informasi yang semakin maju. Kemunculan istilah internasionalisasi khususnya dalam bidang pendidikan di era globalisasi ini diduga muncul karena keempat faktor tersebut.

\section{Upaya Internasionalisasi Universitas di Indonesia melalui Program BIPA pada Era Globalisasi}

Keberadaan bahasa Indonesia saat ini diharapkan mampu menjadi bahasa budaya dan bahasa ilmu pengetahuan dan teknologi yang kuat di tengah dahsyatnya gelombang arus globalisasi. Perlu ditunjukkan sikap terbuka dan tidak kaku 
dalam mengikuti kemajuan global. Masyarakat Indonesia juga diharapkan menunjukkan sikap bangga dan setia sebagai penutur dalam menggunakan bahasa Indonesia sebagai bahasa yang komunikatif dan efektif dalam menghadapi era globalisasi, khususnya di era masyarakat ekonomi ASEAN saat ini (Ngelu, 2015: 159). Salah satu upaya yang dapat dilakukan untuk mewujudkan hal tersebut yaitu melalui pembelajaran BIPA.

Perkembangan bahasa Indonesia bagi penutur asing (BIPA) semakin meningkat di kancah internasional. Hal tersebut dapat dilihat bahwa BIPA tidak hanya diminati di kawasan ASEAN, tetapi juga di wilayah Asia dan Australia. Hal terbukti dengan adanya informasi tentang minat pelajar bahasa Indonesia yang semakin tinggi dari berbagai media cetak maupun daring. Selain itu, BIPA juga dijadikan mata kuliah di beberapa universitas di Eropa, salah satunya di Finlandia (Arumdyahsari, Widodo, dan Susanto, 2016: 828)

Pernyataan tersebut tentu dapat dimanfaatkan sebagai motivasi untuk menjadikan universitas-universitas di Indonesia menuju universitas yang bertaraf internasional melalui program BIPA. Dengan adanya mata kuliah atau bahkan jurusan BIPA dapat dijadikan sebagai salah satu program untuk internasionalisasi lembaga pendidikan tersebut. Selain itu, dengan menjadikan bahasa Indonesia itu sendiri menjadi bahasa internasional juga merupakan upaya untuk menuju internasionalisasi universitas- universitas di Indonesia.

Menurut Suyitno (2008:113) tujuan utama pelajar asing belajar BIPA adalah tentunya selain untuk memperlancar berbahasa Indonesia, juga untuk mengenal budaya Indonesia lebih dalam lagi. Adapun alasan kelancaran berbahasa Indonesia diperlukan oleh para pelajar BIPA karena: (1) para pelajar BIPA tersebut mengambil program tentang Indonesia di universitas asalnya; (2) pelajar BIPA akan melakukan beberapa penelitian di Indonesia; (3) pelajar BIPA akan bekerja di Indonesi; (4) pelajar BIPA akan meneliti masalah tentang bahasa Indonesia; dan (5) pelajar BIPA berencana akan tinggal di Indonesia dalam waktu yang lama.

Dalam penelitian yang dilakukan di Universitas Prima Indonesia (UNPRI) terdapat mahasiswa penutur asing (kelas internasional) di fakultas kedokteran gigi yang sebagian besar berasal dari Vietnam. Mahasiswa tersebut diwajibkan untuk mengikuti mata kuliah BIPA. Menurut Saddhono (2012: 177) dalam penelitian yang telah dilakukan di Universitas Sebelas Maret (UNS) mengungkapkan bahwa mahasiswa penutur bahasa asing dituntut untuk menguasai bahasa Indonesia sebagai bahasa kedua (B2) mereka. Dengan menguasai bahasa Indonesia, pelajar BIPA akan lebih mudah untuk berkomunikasi, baik secara lisan maupun tulisan. Khususnya dalam kegiatan pembelajaran dan mengerjakan tugas akademik di kampus. Oleh karena itu, setiap mahasiswa penutur asing yang belajar di Indonesia, harus mengikuti pembelajaran BIPA agar dapat menguasai bahasa tersebut. Jadi, melalui kewajiban yang harus dilaksanakan oleh mahasiswa asing tersebut dapat dijadikan salah satu pengenalan bahasa Indonesia pada mahasiswa asing lain agar tertarik untuk mempelajarinya.

Menurut Lestyarini

(2012:3) pengembangan kurikulum pembelajaran BIPA harus diupayakan agar sesuai dengan standar internasional dan kondusif 
dalam penyelenggaraannya. Hal tersebut dikarenakan peran bahasa Indonesia yang semakin penting di kancah internasional. Penyelenggaraan pembelajaran BIPA yang berstandar internasional dan kondusif tersebut dapat membantu tercapainya tujuan pembelajaran BIPA itu sendiri. Tujuan yang dimaksudkan antara lain adalah untuk kelancaran proses pembelajaran BIPA dan internasionalisasi universitas-universitas di Indonesia yang mengadakan program tersebut.

Rafiek (2014: 6) mengungkapkan bahwa peluang bahasa Indonesia untuk dikembangkan menjadi bahasa internasional paling tidak di Asia dan Asia Tenggara memang terbuka lebar. Bahasa Indonesia telah diajarkan di beberapa universitas- universitas di luar negeri, misalnya Rusia, Jepang, Amerika Serikat, Australia, Cina, Jerman, dan lain-lain. Sementara itu menurut Soegihartono (2012: 142) pengajaran BIPA telah tersebar di seluruh benua dengan 179 lembaga penyelenggara. Lembagalembaga tersebut misalnya berupa perguruan tinggi, KBRI, pusat-pusat kebudayaan, sekolah Indonesia di luar negeri dan lembaga-lembaga kursus lainnya. Andayani (2015: 401) juga menambahkan bahwa dalam salah satu presentasi sidang pleno Kongres IX Bahasa Indonesia, diungkapkan bahwa pada saat ini ada 45 negara yang ada mengajarkan bahasa Indonesia, seperti Australia, Amerika, Kanada, Vietnam, dan banyak negara lainnya. Sebagai contoh, di Australia bahasa Indonesia menjadi bahasa popular keempat.

Dengan adanya fakta tersebut tentunya dapat membantu upaya internasionalisasi universitas-universitas di Indonesia terutama di era globalisasi ini. Melihat terdapatnya banyak peminat penutur asing yang ingin belajar bahasa Indonesia disertai dengan lembagalembaga yang bersedia untuk mengajarkan bahasa Indonesia di dalam maupun luar negeri tentunya dapat mempercepat internasionalisasi tersebut. Hal tersebut tentunya akan terwujud jika penanganan dan pengelolaannya diselenggarakan dengan sebaik-baiknya.

\section{PENUTUP}

Dari gagasan yang telah disampaikan sebelumnya dapat disimpulkan bahwa penyelenggaraan program BIPA harus disesuaikan dengan karakteristik pelajar BIPA. Hal tersebut dapat disesuaikan melalui tingkat kemampuan masingmasing yang terbagi menjadi tiga, antara lain tingkat pemula, menengah, dan lanjut. Hal tersebut perlu diperhatikan agar pelajar BIPA mampu mengaplikasikan hasil pembelajarannya dalam kehidupan nyata dengan baik dan benar.

Selain dampak negatif, arus globalisasi juga membawa dampak positif bagi kemajuan dunia. Dampak positif tersebut dapat terlihat jika arus globalisasi benar-benar dimanfaatkan demi kemajuan berbagai aspek di dunia, salah satunya yaitu pendidikan. Internasionalisasi di bidang pendidikan merupakan salah satu dampak positif dari adanya globalisasi ini.

$$
\text { Salah satu bentuk }
$$
internasionalisasi di bidang pendidikan adalah dengan diselenggarakannya program pembelajaran BIPA. Seiring dengan adanya upaya internasionalisasi bahasa Indonesia, program BIPA dapat pula dijadikan sebagai salah satu upaya internasionalisasi universitas-universitas di Indonesia. Hal tersebut diiringi dengan bertambahnya mahasiswa asing yang mengikuti program tersebut. Semakin banyak program pembelajaran BIPA, 
semakin banyak pula lembaga khususnya universitas- universitas di Indonesia yang mengadakan program tersebut melalui mata kuliah atau jurusan BIPA.

Saran bagi peneliti selanjutnya adalah agar memuat lebih banyak gagasan dengan disertai teori-teori yang relevan tentang upaya internasionalisasi universitas di Indonesia melalui program pembelajaran BIPA. Kemudian bagi pihak-pihak yang berkaitan dengan BIPA ada baiknya gagasan ini dijadikan pertimbangan untuk membawa program penyelenggaraan BIPA menjadi lebih baik lagi, demi terwujudnya universitas di Indonesia menjadi bertaraf internasional khususnya di era globalisasi ini.

\section{DAFTAR PUSTAKA}

Andayani. (2015). Integrasi Model Pemahaman Budaya Lokal dalam Pembelajaran Bahasa Indonesia bagi Penutur Asing dengan Pendekatan Integratif. Makalah disajikan pada Seminar Nasional dan Launching Adobsi di Universitas Sebelas Maret. Surakarta: ADOBSI.

Arumdyahsari, Sheilla, Widodo Hs, Gatut Susanto. (2016). Pengembangan Bahan Ajar Bahasa Indonesia bagi Penutur Asing (BIPA) Tingkat Madya. Jurnal Pendidikan: Teori, Penelitian, dan Pengembangan, 1 (5), pp. 828-834.

Astika, Gusti. (2015). Globalisasi Bahasa Inggris: So What? Jurnal Bahasa, Sastra, dan
Pengajarannya. 12 (1), pp (8696).

Kusmiatun, Ari. (2016). Mengenal BIPA dan Pembelajarannya. Yogyakarta: K Media.

Lestyarini, Beniati. (2012). Model Sintetik dan Analitik Berbasis Karakter Indonesia dalam Pembelajaran BIPA di Era Global. Makalah disajikan pada seminar Internasional ASILE 2012 dan KIPBIPA VIII LTC-UKSW. Salatiga: Language Training Center Satya Wacana Christian University.

Muliastuti, Liliana. (2016). BIPA Pendukung Internasionalisasi Bahasa Indonesia. Makalah disajikan pada seminar Nasional Politik Bahasa di Universitas Tidar Magelang. Magelang: Untidar

Ngelu, Maria Santisima. (2015). Eksistensi Bahasa Indonesia di Mata Dunia pada Era MEA. Makalah disajikan pada Seminar Nasional Pendidikan Bahasa Indonesia. Surakarta: Universitas Muhammadiyah Surakarta.

Rafiek, M. (2014). Bahasa Indonesia sebagai Bahasa Persatuan Indonesia: Kenyataan, Tantangan, dan Peluang bagi Pengembangan dan Pembinaan Bahasa. Makalah disajikan pada Seminar Kebahasaan dalam Rangka Hari Sumpah Pemuda. Banjarmasin: Balai 
Bahasa Provinsi Kalimantan

Selatan.

Ruskhan, Abdul Gaffar. (2007). Pemanfaatan Keberagaman

Budaya Indonesia dalam

Pengajaran Bahasa Indonesia bagi Penutur Asing (BIPA).

Makalah disajikan dalam

Seminar Pengajaran Bahasa

Indonesia Pertemuan Asosiasi

Jepang-Indonesia di Nanzan

Gakuen Training Center.

Nagoya: Pusat Bahasa

Departemen Pendidikan

Nasional Republik Indonesia.

Saddhono, Kundharu. (2012). Kajian Sosiolinguistik Pemakaian Bahasa Mahasiswa Asing dalam Pembelajaran Bahasa Indonesia untuk Penutur Asing (BIPA) di Universitas Sebelas Maret. Kajian Linguistik dan Sastra, 24 (2), pp: 176-186.

Soegihartono, A. (2012). Pembakuan

Pembelajaran Bahasa

Indonesia bagi Penutur

Asing sebagai Sarana

Pengenalan Budaya

Indonesia. Makalah ini

disajikan dalam

International Conference

on Indonesian Studies.

Depok: Fakultas Ilmu

Pengetahuan Budaya,

Universitas Indonesia.

Suyitno, Imam. (2007). Pengembangan Bahan Ajar Bahasa Indonesia untuk Penutur Asing (BIPA) berdasarkan Hasil Analisis Kebutuhan Belajar. Jurnal Ilmu
Pengetahuan Budaya, 9 (1), pp. 62-78.

Suyitno, Imam. (2008). Norma Pedagogis dan Analisis Kebutuhan Belajar dalam Pembelajaran Bahasa Indonesia untuk Penutur Asing (BIPA). Diksi, 15 (1), pp: 111119.

Thoyib. (2008). Internasionalisasi Pendidikan dan Strategi Pengembangan Mutu Perguruan Tinggi Agama Islam di Indonesia: Sketsa Edukatif Manajemen Mutu. Jurnal Pendidikan Islam El-Tarbawi, 1 (2), pp. 215-234.

Ulumuddin, Arisul, Agus Wismanto. (2014). Bahan Ajar Bahasa Indonesia Ranah Sosial Budaya bagi Penutur Asing (BIPA). Jurnal Sasindo Pendidikan Bahasa dan Sastra Indonesia, 2 (1), pp. 15-35. 